\title{
A Duty to Plan: Proactive Goals of Care Conversations with Seriously III Veterans Who Test Positive for COVID-19
}

J Gen Intern Med 36(11):3636-8 DOI: $10.1007 / \mathrm{s} 11606-021-06837-y$

(C) This is a U.S. government work and not under copyright protection in the U.S.; foreign copyright protection may apply 2021

\section{INTRODUCTION}

The COVID-19 pandemic is highlighting the importance of proactively planning for, having, and documenting goals of care conversations (GoCC) and developing life-sustaining treatment (LST) plans for seriously ill patients, including high-risk patients diagnosed with COVID-19. ${ }^{1,2}$ Proactive GoCC promote a process where patients' values, goals, and preferences are honored and unwanted treatment is reduced. Veterans Health Administration (VHA) is the largest integrated health care network in the USA that requires the documentation of goals of care and LST plans of highrisk patients. Practitioners conduct GoCC with high-risk patients, in both outpatient and inpatient settings, and document LST decisions using a standardized LST progress note template and order set in the electronic health record (details about GoCC process and documentation are reported elsewhere). ${ }^{2}$ Since 2017, VHA clinicians have conducted 425,013 GoCC with unique high-risk patients or their surrogates. We characterized the extent to which patients had GoCC after COVID-19 diagnosis, their LST decisions, and patient characteristics associated with having a GoCC.

\section{METHODS}

We obtained data from VHA's Corporate Data Warehouse (CDW) as of November 1, 2020, on all COVID-19-positive Veteran patients $(n=88,562)$, their demographics, health conditions $^{3}$, and documentation of GoCC prior to and following COVID-19 diagnosis. Because VHA promotes GoCC among patients with a high risk of hospitalization or death within the year (as defined by VHA's Care Assessment Need (CAN) Score of 95 or higher), we restricted our analyses to these patients $(n=8982)$. Detailed information about CAN scores and prioritizing patients with CAN scores of $95+$ for $\mathrm{GoCC}$ is reported elsewhere. ${ }^{2,4} \mathrm{We}$ conducted descriptive analyses to

Received December 29, 2020

Revised February 19, 2021

Accepted April 20, 2021

Published online May 4, 2021 characterize patient characteristics in our sample and logistic regression to identify factors associated with the probability of receiving a GoCC following diagnosis. For both descriptive analyses and logistic regression, we used R: A language and environment for statistical computing. ${ }^{5}$ This work was not subject to IRB approval because it was deemed a quality improvement analysis for VHA's Life-Sustaining Treatment Decisions Initiative.

\section{RESULTS}

We identified 8982 COVID-19 positive Veteran patients with a CAN score of 95 or higher. Ninety-five percent were male; median age 73 years; $30 \%$ Black or African American; 7\% Hispanic or Latino; 64\% White; and 41\% married. Sixty percent of these patients had cardiovascular disease; $61 \%$ frailty; $31 \%$ cancer; $24 \%$ dementia; $9 \%$ end-stage lung disease; and $9 \%$ end-stage renal disease. Twenty-one percent $(n=1886)$ had a GoCC subsequent to COVID-19 diagnosis within a median of one day (IQR 0-6) (data not shown). Fifty-one percent $(n=968)$ indicated do-not-resuscitate (DNR/DNAR) for cardiopulmonary arrest and $21 \%(n=397)$ indicated limits to mechanical ventilation for respiratory failure (Table 1). Thirty percent of patients who had a GoCC subsequent to COVID-19 diagnosis also had a previous GoCC. Of the 7096 patients that did not have a GoCC subsequent to COVID-19 diagnosis, 37\% had a prior documented GoCC. Factors statistically significantly associated $(\alpha=0.1)$ with having a GoCC after COVID-19 diagnosis wereprior GoCC, higher CAN score, older age, end-stage renal disease, frailty, and Black race. Female patients and those with dementia were less likely to have had a GoCC subsequent to COVID-19 diagnosis (Table 2). Of the 39\% ( $n=3502)$ Veterans with a GoCC prior to COVID-19 diagnosis, $7.8 \%$ changed preference for LSTs: $5.5 \%$ changed from full code to DNR/DNAR and $2.3 \%$ from DNR/DNAR to full code (data not shown).

\section{DISCUSSION}

Proactive GoCC for rising numbers of COVID-19 cases may help promote goal-concordant care by identifying patientcentered preferences for LSTs, including preferences to limit 
Table 1 Life-Sustaining Treatment (LST) Decisions and Clinical Setting of Goals of Care Conversations (GoCC) Following COVID-19 Diagnosis among Patients with CAN Score 95+ $(n=1886)$

\begin{tabular}{lll}
\hline \hline $\begin{array}{l}\text { Code status (in the event of } \\
\text { cardiopulmonary arrest) }\end{array}$ & CPR-full code & $\begin{array}{l}918 \\
(48.7)\end{array}$ \\
& DNAR/DNR & $\begin{array}{l}968 \\
(51.4)\end{array}$ \\
$\begin{array}{ll}\text { Mechanical ventilation (in the } \\
\text { event of respiratory distress or } \\
\text { failure when the patient has a } \\
\text { pulse) }\end{array}$ & $\begin{array}{l}\text { Limit mechanical } \\
\text { ventilation as specified }\end{array}$ & $39(2.1)$ \\
& $\begin{array}{l}\text { No invasive mechanical } \\
\text { ventilation }\end{array}$ & $346(18.3)$ \\
& $\begin{array}{l}\text { No non-invasive me- } \\
\text { chanical ventilation }\end{array}$ & $12(0.60)$ \\
Clinical setting of GoCC & $\begin{array}{l}\text { Outpatient } \\
\text { Emergency department }\end{array}$ & $138(7.3)$ \\
& Inpatient & 1689 \\
& Telephone & $(89.6)$ \\
& & $18(1.0)$ \\
\hline
\end{tabular}

cardiopulmonary resuscitation and mechanical ventilation and thus avoid providing potentially limited resources to those who do not want them. Although this study did not examine the extent to which Veterans' preferences for care were honored, previous research has demonstrated associations between GoCC and care received in VHA. ${ }^{6}$ For patients with a documented GoCC prior to COVID-19 diagnosis, such a diagnosis may be an inflection point - suggesting the need to revisit these patients' goals and decisions due to changing or worsening clinical conditions. Our analysis reflects the pandemic up until the beginning of November 2020. Future work should assess GoCC rates across the pandemic, the extent to which Veterans receive goal-concordant care, and effective strategies to increase GoCCs during COVID-19 (e.g.,

Table 2 Predictors of Goals of Care Conversations (GoCC) Subsequent to COVID-19 Diagnosis among Patients with CAN Score $95+(n=1886)$

\begin{tabular}{|c|c|c|}
\hline Variable & $\begin{array}{l}\text { Odds ratio ( } 95 \% \text { confidence } \\
\text { interval) }\end{array}$ & $p$ value \\
\hline $\begin{array}{l}\text { Intercept } \\
\text { Male (Reference) }\end{array}$ & $0.18(0.15,0.21)$ & $<.0001$ \\
\hline Female & $0.72(0.53,0.96)^{-}$ & $0.0 \overline{3}$ \\
\hline Age & $1.03(1.02,1.03)$ & $<.0001$ \\
\hline $\begin{array}{l}\text { Race White } \\
\text { (reference) }\end{array}$ & - & - \\
\hline Race Black & $1.20(1.07,1.35)$ & $<.0003$ \\
\hline Race other & $1.27(0.87,1.82)$ & 0.20 \\
\hline $\begin{array}{l}\text { Not Hispanic } \\
\text { (reference) }\end{array}$ & - & - \\
\hline $\begin{array}{l}\text { Hispanic } \\
\text { Married (reference) }\end{array}$ & $1.18(0.96,1.45)$ & 0.10 \\
\hline Divorced/separated & $0.98(0.87,1.11)^{-}$ & $0.7 \overline{7}$ \\
\hline Single & $1.08(0.91,1.29)$ & 0.38 \\
\hline Widowed & $0.99(0.84,1.16)$ & 0.86 \\
\hline $\begin{array}{l}\text { CAN 95-97 } \\
\text { (reference) }\end{array}$ & - & - \\
\hline CAN 98-99 & $1.26(1.13,1.41)$ & $<.0001$ \\
\hline Prior GoCC & $1.19(1.08,1.33)$ & $<.002$ \\
\hline $\begin{array}{l}\text { End-stage renal } \\
\text { disease }\end{array}$ & $1.27(1.06,1.52)$ & 0.01 \\
\hline Cardiovascular disease & $0.96(0.86,1.07)$ & 0.48 \\
\hline Frailty & $1.28(1.15,1.43)$ & $<.0001$ \\
\hline End-stage lung disease & $1.08(0.90,1.30)$ & 0.42 \\
\hline Dementia & $0.86(0.76,0.98)$ & 0.02 \\
\hline Cancer & $0.97(0.87,1.08)$ & 0.57 \\
\hline
\end{tabular}

telehealth), especially amongst patient groups that were less likely to have had a GoCC.

Jennifer Cohen, $\mathrm{PhD}, \mathrm{MPH}^{1,2}$

Mary Beth Foglia, RN, PhD, $M A^{1,3}$

Adam Batten, $\mathrm{BS}^{4}$

David Alfandre, MD, MSPH ${ }^{1,5}$

${ }^{1}$ Department of Veterans Affairs, National Center for Ethics in Health Care, Veterans Health

Administration,

Washington, DC, USA

${ }^{2}$ Department of Epidemiology, University of Washington School of Public Health,

Seattle, WA, USA

${ }^{3}$ Department of Bioethics and Humanities, University of Washington School of Medicine,

Seattle, WA, USA

${ }^{4}$ Seattle Institute for Biomedical and Clinical Research,

Seattle, WA, USA

${ }^{5}$ Department of Population Health, New York University School of Medicine,

New York, NY, USA

Corresponding Author: Jennifer Cohen, $\mathrm{PhD}, \mathrm{MPH}$; Department of Veterans Affairs, National Center for Ethics in Health Care, Veterans Health Administration, Washington, DC, USA (e-mail: jennifer.cohen@va.gov).

Author Contribution Study concept and design: Cohen, Foglia, and Alfandre. Acquisition of data: Cohen and Batten. Analysis and interpretation of data: Batten, Cohen, Foglia, and Alfandre. Drafting of the manuscript: Cohen, Foglia, and Alfandre. Critical revision of the manuscript for important intellectual content: Cohen, Foglia, Alfandre, and Batten. Obtained funding: $n / a$. Study supervision: Cohen.

Funding This study was supported in part by resources from VA's National Center for Ethics in Health Care.

\section{Declarations:}

Conflict of Interest: The authors declare that they do not have a conflict of interest.

Guarantor Statement: Dr. Cohen had full access to the data in the study and takes responsibility for the integrity of the data and the accuracy of the data analysis.

Financial Disclosures: No financial disclosures were reported by the authors of this paper.

Role of the Sponsor: This study was supported in part by resources from VHA's National Center for Ethics in Health Care. The funding organizations had no role in the design and conduct of the study; the collection, management, analysis, and interpretation of the data; or the preparation, review, or approval of the manuscript.

Other contribution: We thank Lucy Potter, MSW, and Sandy Brooks, DPS, of the VHA National Center for Ethics in Health Care for their roles in reviewing this work in the context of VA's Life-Sustaining Treatment Decision's Initiative.

Disclaimer: The views expressed herein are those of the authors and do not necessarily represent the position or policy of the U.S. Department of Veterans Affairs, the United States government, or VHA National Center for Ethics in Health Care. 


\section{REFERENCES}

1. Curtis JR, Kross EK, Stapleton RD. The Importance of Addressing Advance Care Planning and Decisions About Do-Not-Resuscitate Orders During Novel Coronavirus 2019 (COVID-19). JAMA. 2020;10.1001/ jama.2020.4894.

2. Foglia MB, Lowery J, Sharpe VA, Tompkins P, Fox E. A Comprehensive Approach to Eliciting, Documenting, and Honoring Patient Wishes for Care Near the End of Life: The Veterans Health Administration's Life-Sustaining Treatment Decisions Initiative. Jt Comm J Qual Patient Saf. 2019;45(1):4756.

3. Wachterman MW, Pilver C, Smith D, Ersek M, Lipsitz SR, Keating NL. Quality of end-of-life care provided to patients with different serious illnesses. JAMA Intern Med 2016;176(8):1095-1102.
4. Wang L, Porter B, Maynard C, et al. Predicting Risk of Hospitalization or Death Among Patients Receiving Primary Care in the Veterans Health Administration. 2013;51(4):368-373.

5. R Core Team. R: A language and environment for statistical computing. $\mathrm{R}$ Foundation for Statistical Computing, Vienna, Austria. 2014. Available at: http://www.R-project.org/. Accessed April 30, 2020.

6. .Miller, Susan C., et al. "Honoring Veterans' Preferences: The Association Between Comfort Care Goals and Care Received at the End of Life." Journal of Pain and Symptom Management (2020).

Publisher's Note: Springer Nature remains neutral with regard to jurisdictional claims in published maps and institutional affiliations. 